\title{
Globalisation, transnational academic mobility and the Chinese knowledge diaspora: An Australian case study
}

\author{
Rui Yang ${ }^{a *}$ and Anthony R Welch ${ }^{b}$ \\ ${ }^{a}$ University of Hong Kong, ${ }^{b}$ University of Sydney
}

\begin{abstract}
The master discourses of economic globalisation and the knowledge economy each cite knowledge diasporas as vital 'trans-national human capital'. Based on a case study of a major Australian university, this article examines the potential to deploy China's large and highly-skilled diaspora in the service of Chinese and Australian scientific and technological development. It finds that at a time when much of the world is deeply mired in a global financial crisis, this treasured resource of highly-skilled intellectuals assumes even greater significance. Meanwhile, there are key challenges to be confronted to fully utilise China's overseas talent. It argues that the Chinese knowledge diaspora are a modern kind of cosmopolitan literati, and could contribute actively to higher education internationalisation in both Australia and China.
\end{abstract}

Key words: Globalisation, Transnational ism, Academic Mobility, Knowledge Diaspora, China, Higher Education

\section{Introduction}

In an era when the knowledge economy is increasingly global in form, China is competing vigorously to strengthen its innovation system, of which its universities are a key element. Among China's strategic advantages, the huge resource represented by its own highly-skilled diaspora is a key example. Recognising the potential of this resource, and in an era of skills shortages in key arenas, countries of migration, such as Australia, Canada and the USA have targeted their migration schemes at high-skill individuals, many of whom are mainland Chinese (Hugo, 2006). A large number of mainland Chinese intellectuals work at universities abroad, often after having taken their PhDs in such countries (Welch \& Zhang, 2007). As knowledge carriers and producers, they are valuable human capital and are a target of national migration and innovation policies (Kuptsch \& Pang, 2006). Those working in Australian universities become important assets to both Australia and China. However, there has been little research on them, especially in local contexts and in relation to broader axes of spatial relations in state and society (Cartier, 2003). Based on a case study of Ivy University (a pseudonym), this article examines the potential to deploy China's large and highly-skilled diaspora in the service of Chinese and Australian scientific and technological development.

\footnotetext{
${ }^{*}$ Corresponding author: Faculty of Education, University of Hong Kong, Pokfulam Road, Hong Kong. Email: yangrui@hkucc.hku.hk
} 
The choice of Ivy is based on its membership of Australia's elite category of universities situated in a capital city. It is both a major employer and a key institution within the city and the state. Highly respected both domestically and globally, it attracts significant numbers of international students, mainly from within the Asia-Pacific region, with China as the largest single source of its international students. Australia's unique location in the Asia Pacific, relatively close to China, is part of the reasons for so many students choosing Ivy (and Australia more generally), and among some Chinese staff, it is also seen as an advantage. For academics, lifestyle is sometimes given as another pull factor behind their decision to work in Australia.

\section{Diaspora, knowledge mobility and globalisation}

The term diaspora stems from Greek. Those who settled in new lands were regarded as diesparmeynoi (the etymology of the term reflects the act of scattering seed), and were referred to as tho Ellenikho (part of the Greek collective), affirming their common cultural identity. The ancient Greeks used it to describe the colonisation of Asia Minor and the Mediterranean in the Archaic period (800-600 BC) (Reis, 2004). Diaspora was later used to denote the dispersion of Jews outside Israel from the $6^{\text {th }}$ century BC, when they were exiled to Babylonia. The word thus connotes the loss of homeland, uprootedness, expulsion, oppression, a collective memory of the homeland and a strong desire to return to it one day. It has now widened to include political refugees, guest workers, alien residents, expellees and overseas communities (Shuval, 2000, p. 42).

In comparison with other types of migration, a diaspora is a system of personal networks, shared culture and language, and an imaginary relationship to the homeland (Kapur, 2001, p. 5). While maintaining an identity and connection to the home country, it is a means of channelling the economic resources of the overseas diaspora to encourage investment and entrepreneurial activity in the homeland (Reis, 2004; Lucas, 2001). As globalisation intensifies, the elements such as the loss of homeland, a collective memory of oppression and the gnawing desire for return have been suppressed, while other connotations such as hyper-mobility and flexible identities on the part of transmigrants as well as multiculturalism and transnational flows of capital, have been elevated. They now maintain multiple relations - familial, economic, social, organisational, religious, and political - that cross borders (Ma \& Cartier, 2003).

The language of diaspora emphasises the importance of homeland and entails fluidity, transnationality and economic-driven characteristics that emphasise the equal importance of hostland and the social transactions between homeland and hostland (Wong, 2006). Global knowledge diasporas, sustained by both increases in global migration flows and the rise and increasing ubiquity and density of information and communication technologies (Welch \& Zhang, 2007), are, inter alia, a form of transnational human capital in the new millennium. They become more valuable in a context of fast-increasing geographical mobility and worldwide communication linked to globalisation (Zweig, Chen \& Rosen, 2004). There is an urgent need for examining the contributions they make to both their homeland and the new land, and what factors that influence their knowledge work.

Universities embed themselves deeply in cross-border flows of knowledge workers. The new global cultural economy is a complex, overlapping, disjunctive order (Appadurai, 2001), with flows of cultures hardly bounded within nation-states but moving across national boundaries to the global. Within these processes, transnationalism emerges amongst diasporic 
networks of ethnically and culturally distinctive peoples. The knowledge diaspora is able to interrogate the global through the local and contribute to the creation of 'in-between' cultural spaces above the boundary of nation-states (Rizvi, 2000). Universities as transnational platforms for knowledge diaspora work are essential organisations that create, transmit, reproduce and receive cultural messages or practices which support mobility and the deployment of cultural power. While rooted in their own cultures and affected by national realities, they are part of an international knowledge system, and interact with institutions and ideas from abroad.

For China, however, deploying the diaspora option is now a priority, representing a more nuanced response to issues of brain drain (Zweig, 2006). The number of Chinese students taking degrees abroad has risen significantly over the past decade, from little more than 20,000 in 1997, to 140,000 in 2007. While it is true that return rates have been rising of late, from around 6,000 in 1997 to almost 45,000 in 2007 (Welch \& Cai, 2010), as more and more opportunities open up in China's dynamically growing economy, it is still the case that a significant percentage of those who study abroad will remain overseas, and indeed there is some evidence that the very brightest are most likely to do so (Cao, 2004). They are an underexploited resource, expected to be able to play a vital role in China's next stage of development and accelerate the integration of the Chinese academy into the international community.

This too must be seen in context. As has long been pointed out, the international knowledge system is fundamentally unequal (Altbach, 1998). A few countries at the centre retain extraordinary academic power, while the rest remain on the periphery or semi-periphery. The lack of well-trained academic personnel is a major factor for the peripheral countries failing to move closer to the centre. Flows of intellectuals are still very largely from the South to the North. With such global inequality of knowledge creation and application, wealthy countries of the global North compete to attract research talents from poorer countries of the South (Solimano, 2002), whose best and brightest then consolidate the already-strong knowledge base in the former (Hugo, 2002), at the cost of the latter (Grubel, 1987; Kapur \& McHale, 2005). While the mobility of the highly skilled could raise the total world output, and benefit the world as a whole (Johnson, 1968), the international mobility of human capital tends to result in a loss of

technological development and economic growth for sending countries (Dzvimbo, 2003; Mullan, Politzer \& Howard, 1995; Partinkin, 1968).

Nevertheless, the non-unilateral, complex, overlapping and unpredictable characteristics of globalisation indicate that the distribution of power is fluid and changing. The worldwide circulation of the highly skilled, itself an important part of the global knowledge system, can consolidate host countries' research hegemony, but alternatively modify global asymmetries and unidirectional flows. The hierarchical structure in knowledge distribution and dissemination has become less fixed, as loci of power and growth become more multi-polar, and dispersed (Meyer, Kaplan \& Caran, 2001). Our wider research in Canada and Australia, showing that almost irrespective of family history, or personal views, the Chinese knowledge diaspora is eager to assist China's development, and makes efforts to do so, underlines that the diaspora option can be instrumental in narrowing the North-South scientific gap (Kuznetsov, 2006; Meyer \& Brown, 1999; Zweig, 2006; Zweig, Chan, \& Rosen, 2004). There is some evidence that the Chinese knowledge diaspora maintain stronger academic links with the homeland, than their Indian peers (Hugo \& Dasvarma, 2008)

The global mobility of the highly skilled has long been a matter of national concern, and continues to raise welfare and economic development issues (Auriol \& Sexton, 2002; Bhagwati \& Rodriguez, 1975; Grubel, 1987; Lucas, 2001; Olesen, 2002). Recent literature has drawn 
attention to some of the potential benefits of technology transfer, trade and capital flows induced by 'brain drain' (Gaillard \& Gaillard, 1998; Saxenian, 2006; Solimano \& Pollack, 2004). The term 'brain exchange' implies 'a two-way flow expertise between a sending country and a receiving country’ (Salt, 1997, p. 5). The new concept of ‘brain circulation’ refers to flows of expertise between sending and receiving countries in a way that mutually benefits both sides (Mahroum, 1999).

While still coping with brain drain, sending countries now increasingly recognise diaspora as a channel for technology transfer. With a strong attachment to their homelands, the diaspora can create networks to connect professionals and scientists around the world to help promote scientific and economic development in their home countries (Solimano, 2002). For instance, grassroots initiatives in South Africa and Latin America have been developed to link researchers abroad to networks in their home countries. Indian professionals in the United States have been the primary driving force in the transfer of knowledge to India (Cervantes \& Guellec, 2002; Saxenian, 2006). The global network of highly-skilled Korean scientists and engineers strengthens Korea's links with key host countries (Namgung, 2009). Even without permanent repatriation, the knowledge diaspora still transfer expertise and skills to their countries of origin and strengthen the connection between their host and home countries.

\section{The study}

Purposive sampling was employed to ensure adequate representation of different disciplines, ranks, and men and women. All 16 interviews were conducted by the authors on campus in 2009. Reflecting wider patterns among the Chinese knowledge diaspora, most interviewees were from the sciences, including medicine and health, but every effort was made to recruit and interview those from the social sciences and humanities. Ages varied from around 30 to about 60 years, and ranks from Lecturer to Associate Professor. Despite considerable efforts being made to recruit and interview females for the study, the large majority of interviewees were male, perhaps reflecting in part, the dominance of Chinese staff in more 'male' areas such as the sciences. A semi-structured interview, consisting of a number of key themes provided a degree of reliability, but also flexibility, allowing interviewees to provide more details, and authors to follow up, where required.

\section{Major findings}

In consideration of the unique features of the Chinese knowledge diaspora and based on the data collected from the interviews, the following section presents major findings:

\section{Advantages and disadvantages of pursuing an academic career in Australia}

It is not surprising that the Chinese knowledge diaspora mainly choose where to pursue their professional career based on perceived opportunities. Most of them tend to stay within the system where they complete their doctoral studies. This might be due to the network they built up during their studies. The most important reasons for them to stay are career opportunities and 
living and work environments, as the following quotes illustrate:

I started my career here. At that (graduation) time, I considered the option of going back. But I didn't. This is not only due to academic development, but also in consideration of environment and life. (InterviewCQE-4)

Advantages are obvious. In Australia, institutions have better resources and facilities in terms of research equipment, funding, and library information. Here, it is really easier to communicate with other people outside Australia, in the U.S. and Europe. This is probably the main advantage. (Interview-SCW-2)

Among the 15 interviewees, two received their PhDs from North America, one each from the UK, Singapore, Canada and China, with nine from Australia. When asked about the reasons for their coming to Ivy, one female participant whose $\mathrm{PhD}$ was from a major American university said,

This is a place for family life. It's convenient for us to live here than in Texas. Teaching load here is not that much heavy as in North America. These are major attractions to us. As for research, it's quite good here.

Our faculty is wealthy, with good resources. (Interview-ASS-11)

Ivy's international reputation is also an important factor that they consider seriously in making their decisions about where to pursue their career. As one respondent said,

Why I came here? I think, first of all, the university is very highly ranked in my area. It provides me with a better environment to make some purely academic research. (Interview-CAE-1).

Often our participants cited the lack of much Guangxi (the Chinese social and cultural system based on valuing personal relationships) as another advantage of working in Australia, as expressed by the following interviewee:

One advantage is you are totally free here. Even though you have a boss, probably the chair of your department or a professor, they give you total freedom to do whatever you like in science. So that's one of the best advantages here. (Interview-IYY-13).

When asked whether or not she would go back if a Chinese university offers her a good job, Interview-ASS-11 said:

I'd go back as a visiting scholar, but not on a permanent basis. The academic atmosphere in the mainland is not so good, and the issue of Guanxi is often too complicated. Since we have been away for quite a long while, it can be difficult for us to relocate and fit into the Chinese system. I won’t consider going back permanently.

Two other participants with Australian PhDs made similar comments:

I worked in China for a while before I came to Australia. So I can see the differences. Guanxi is much less complicated here. (Interview-CQE-4)

They have offered me a job since 1997. Every year, they ask me to go back (permanently). There is too much politics and internal fighting (there). (Interview-IZE-15)

When considering going back to China, 'complicated' was the word used repeatedly by the 
participants. Most of the complications related to family issues. Among them education for their children predominated, as shown by the following:

I came to Australia in 1988. My top and foremost consideration is my child. He has been here for quite a while, without good Chinese proficiency. It is quite difficult for him to fit into the mainland education system after being taught here for many years. (Interview-CGS-7)

With substantial experience in western countries, both they and their children are more used to a western work and education environment. It is therefore easier for them to move to another western country than moving to China. For example, when asked if he would be interested in jobs offered in the USA, Interview-MZS-10 said: 'It depends on the position. If it is a good position, I'm open to take it.' He continued to say that 'There would be problems with the family if we move back to China. We could move to England, to the U.S., but it's more difficult to move back to China.'

Similarly, when asked if he would take a post offered by a top Chinese university, Interview-IYY-13 said: 'We have been very well settled here. Due to family matters, I think it'd be very hard. My daughter grows up here. She wouldn’t go anywhere else.' When asked about jobs coming up in Toronto, Los Angeles, or New York, he said: 'Maybe, it is more appealing to me.'

In contrast to most of our participants who are usually in their 50s and late 40s and have become established in Australia, some younger ones express quite different calculations. Although they are still working in Australia, they consider the option of going back to China to develop their career much more seriously. Indeed, they are waiting for opportunities. For example, when asked if he would leave Ivy for a post by China, Interview-CZE-9 who was 30 by the time of interview said 'It depends on what kind of position it is. If it's good with better salary, I’d definitely go back.'

Similarly, another interviewee, also in his early 30s, remarked:

I have not yet decided to live and work here in Australia. For me, I'm inclined to go back to China, but the point is how and when I can go back. (Interview-BSS-12)

There are various disadvantages. Among them, the most reported has been the English language. The fact that the academic culture is very heavily English language based at Ivy makes a significance difference in terms of their work and communication with overseas. As illustrated by Interview-CAE-1, 'As a Chinese, I think English is always a barrier. I don't think this affects our research. But it affects my teaching a lot.’

The biggest disadvantage for us is the English language. I was 20 when I started to learn it. We have to work much harder than our Australian peers to achieve equally. (Interview-SCW-2)

I think our biggest disadvantage is the English language. We learned everything in Chinese, but here everything changed into English. (Interview-ZHY-6)

Even though I have been here for more than 20 years, the language is still the main barrier to go further. It always means you can never go 100\%. That’s a big disadvantage for us. (Interview-IYY-13)

Research collaboration with China 
Previous studies have shown that cultural and linguistic backgrounds contribute to closer scholarly communications. Among intellectual diasporas, there is a strong positive sentiment regarding cooperation with the home country (Meyer, Kaplan \& Caran, 2001). Choi (1995) also observed that many Asian background academics in American higher education kept close contact with their countries of origin, maintaining scientific and academic relationships with colleagues and institutions at home. Considering their Chinese background and their social and academic networks in China, one hypothesis was that the Chinese knowledge diaspora would work particularly well in research collaborations with China.

This study, however, has found that, although all the participants expressed their interest in research collaboration with China, and most of them have maintained contacts with their friends, family and colleagues there, the extent of actual research collaboration varied significantly. To some, an overwhelming majority of their international research collaboration is with China. For example, Interview-CAE-1 estimated that $90 \%$ of his internationally joint research was with China, while Interview-SCW-2 had 70\% with China and the other 30\% with overseas Chinese. Interview-MZS-10 reported 'quite much collaboration with mainland Chinese, the Chinese in Australia, and overseas Chinese academics'. For others, such collaboration was very limited. For example, both Interview-CGS-2 and Interview-CZE-9 reported almost no research collaboration with mainland Chinese scholars.

There are many reasons for both variations in research collaboration, both with mainland Chinese, and overseas Chinese, scholars. Among those with substantial research collaborations with China, their previous academic networks in China often play an effective role in stimulating research collaborations, especially since the 1990s when China began to accelerate the integration of its scholarly circle into the international community. The Chinese intellectual diaspora is an ideal agent to liaise between Chinese and western academic communities, and assist the mainland to enter into the global knowledge system by joint projects and publications in mainstream international journals. Such knowledge bridges are in part responsible for China's rapidly rising scientific stature $(\mathrm{Li}, 2005)$.

For some, the need to work with China is partially due to Australia's geographical isolation, as one participant with her $\mathrm{PhD}$ from the USA remarked,

It is a bit isolated here. I think academics here have stronger intention to communicate with China. (Interview-ASS-11)

When asked how often they keep in touch with mainland and overseas Chinese scholars, the following response by interviewee-CAE-1, who had collaborations with mainland Chinese scholars and the Chinese colleagues in Australian and U.S. universities, was typical:

I would say very, very frequently. I keep very good contacts with my colleagues at Tsinghua, as well as many friends in the industry and government. For example, my friends came here for a visit or do research, and sometimes we work on some cooperative proposals for some international funds.

As for the forms of communication, their collaboration includes nearly all the possible forms: conferences, cooperative research, student exchange, staff visits, exchange of research papers and so on:

Actually all of those forms, for example, one professor at Ivy and I work together to run a research network which consists of many Chinese academics. We organise such activities as conferences and training workshops, research projects. (CAE 1) 
While communication is more ubiquitous and advanced technology is making it easier, there are still some issues. The establishment of research collaboration with China, while underpinned by university incentive schemes (notably among top-tier institutions), and government programmes such as 985, Hundred Talents, Thousand Talents and 111 (Welch \& Cai, 2010) requires more than passion. Indeed, it was affected by various factors at multiple levels, which are often out of their control. For example, Interview-BSS-12 said,

I don’t have any concrete collaboration with mainland Chinese scholars, but I am willing to set up any sort of collaboration. The problem is often the networking. I do not know them and they do not know me.

Even after both sides meet, often there is little subsequent follow-up: 'I had some communication with one mainland scholar after a conference. Then he moved, and we lost contact. Collaboration is easier said than done.'

Interview-CQE-4 echoed these sentiments:

I do not have much collaboration with mainland Chinese scholars. I always try to set up connections with them. It's quite difficult to find opportunities. I'm not quite clear why some people can set up their connections quickly. I have met a few mainland scholars in my area when attending international conferences. I paid a visit to Fudan. But it was merely a visit. There was no concrete collaboration afterwards.

While every participant expressed her/his interest in conducting collaborative research with China, a number of factors restrict the fulfilment of these intentions. Replying to a question regarding the barriers to actually making the networks with China operate successfully, the participants often mentioned over-commercialisation in China's contemporary scholarly circles, as illustrated by Interview-CAE-1 and Interview-SCW-2:

Professors have more pressure to survive in their life. I mean financial life. Many are in fact very good, but they just can't focus on research. (Interview-CAE-1)

In China, some top scientists are not interested in doing the real work, almost like brokers. They take certain percentage of their research grants. They like to do consultancy. Once people become famous they always want to assess projects, review proposals and go to meetings to get paid. This tendency is growing, compared to years ago. (Interview-SCW-2)

Another restrictive factor is the availability of Chinese Data. When asked if they could obtain research data from China's ministries or through their Guanxi with Chinese colleagues, Interview-SCW-2 said:

In China, getting data is terrible. You can’t get data from them. You have to buy them, and very expensive. You have to do backdoor. If you follow Chinese government regulations, they (the data) should not be released. Sometimes, China has some old silly policies which were set up many years ago. (InterviewSCW-2)

A further factor is the stratification of Chinese higher education institutions. For example, when working with Chinese institutions, Interview-SCW-2 emphasised the gap between top and regional universities. According to him, 
The top Chinese scientists are world level without doubt. But the quality of the researchers at provincial universities is very poor. It is not just their scientific level, but also their English proficiency and attitude towards research.

Interview-IYY-13 made relevant comments on this:

There are major differences between Chinese universities. The top ones are very similar to those in western countries and are easy to work with. Their research is at top level.

\section{Cultural identity}

In terms of the cultural identity of the Chinese knowledge diaspora at Ivy, most of the characteristics of diasporas such as dispersion, hyper-mobility and memories of the homeland were evident, while political exile was, with almost no exception, strongly rejected. As to perceptions of how settled they are in Australia and whether they feel alienated, different responses were evident. While largely happy and comfortable with their current working and living situation, some indicated that the issue of integration into the so-called mainstream Australian society was not significant enough to affect their life and work. As indicated in the following quotes, most felt that Australia's multicultural social environment afforded them sufficient possibilities:

The university life here is multicultural. The environment and people around are quite nice. (InterviewMZS-10)

I think discrimination is unlikely to occur in universities because the education level is much higher. (Interview-CQE-4)

Another even reported not paying much attention to the issue of mainstream society:

I have hardly thought of this. I am doing research here. It doesn't matter much regarding the issue of socalled mainstream society. We are scholars and researchers. I don’t think people like us consider it very much. (Interview-CZE-9)

A third respondent, a senior scholar, gave a more nuanced reading of prospects for Chinese scholars working in a non-Chinese environment:

One of my concerns is promotion to the highest level. Race is a more or less inevitable factor. This is not to say that racial discrimination exists. Since you are a member of [a] minority and English is not your native language, it can be inconvenient for you in terms of communication. Being a top level professor, leadership seems much important. It is difficult for you without the native background and culture understanding. You may not fully understand the culture and customs. (Interview-MZS-10)

Some even challenged the meaning of the mainstream Australian society. For instance, Interview-IYY-13 said,

I think actually myself, I am the mainstream. I'm never worried about this. Some people in the Chinese community deliberately try to join the mainstream. Who is the mainstream? If you work at a university, you are deeply embedded in the mainstream. I even don't notice I am not in the mainstream. 
Their responses challenge the notion that migrants from China are not able to embrace an alternative environment, due to the effects of a lack of genuine interest in Australia and a totalitarian Chinese society (Gilbert, Khoo \& Lo, 2000). Their feeling of alienation in Australia was not significant. On the contrary, they can be argued to be a bridge between East and West: after living and working overseas for years, with knowledge acquired from both Chinese and western societies, they have created ways to enact individualism, and combine Chinese spiritual tradition with secular western knowledge (Wang, 2001). They are cosmopolitan, rich in international experience, and can work well in various societies and culture, as illustrated by a young engineer who had lived in China, Singapore, the USA and Australia:

\footnotetext{
Maybe I do not care. I don't have the desire to get into the mainstream, because I'm pretty international. I have kind of advantage. I'm from China and visited many places. I always think I'm a kind of international person. I don't belong to any single country. (Interview-CAE-1)
}

\section{Enter the dragon? China's dramatic rise on knowledge and innovation indices}

China is fast becoming a global player in world scholarship. Its emerging international visibility in natural science and engineering is dramatic. China's overall representation in the international scientific community has grown rapidly since reopening to the world. The number of papers by China's scholars appearing in prestigious mainstream natural and social science journals grew from 1,293 in 1981 to 11,435 by 1995, and to 41,596 in Science and Engineering alone by 2005. They were cited 8,517 times in 1981-85, but 77,841 times for the period 1993-97 (World Bank, 2000). China's share of world scientific publications rose from $2 \%$ to $6.5 \%$ over the decade ending in 2004, and China already ranks second, behind the United States, in world publications on Nanotechnology. Equally, Chinese patent applications now account for 3\% of applications filed under the Patent Cooperation Treaty (PCT) of the World Intellectual Property Organization (WIPO) and are doubling every two years (OECD, 2008). Whereas China's share of Science and Engineering articles in 1998 was $1.6 \%$ of the world total, this had risen to 5.9 per cent by 2008 . Citations rose from 0.6 per cent of world total to 4.3 per cent, over the same period (NSF, 2010) At the system level, according to the Academic Ranking of World Universities conducted by the Graduate School of Education, Shanghai Jiaotong University (2007), China has Tsinghua and Peking universities in the top 200; Nanjing, University, Shanghai Jiaotong, the University of Science and Technology of China, and Zhejiang in the top 300; and a total of 14 universities that feature in the top 500 .

Given such impressive developments, more and more mainland Chinese academics are acknowledged as experts in various fields:

\footnotetext{
One change I have noticed is more Chinese names appear in our professional journals, especially in the very top ones. You will be very surprised to see any journals without any Chinese names as the first author. You see some like Cell, there are 20 papers, at least 3 are under Chinese names, and even more. They are mainly people working outside China. But more and more scholars in China are publishing very good papers. About 10 years ago, there were very few, but now you can see more and more. (IYY-13)
}

This increases the need for the Chinese knowledge diaspora to work with China, as demonstrated by the following remarks by our interviewees:

Our colleagues in China also read western theories and use the books as well. So we can easily have some 
common ground. We can easily have a common framework of reference. My area, architecture, is incredibly hot and active in China. All the well-known scholars and architects in the world want to study China, visit China, and do something in China. The scholars in China are increasingly becoming more international than I am. They see more interesting people than I can do here. It's so dramatic. Every year, they just go up and up. (Interview-AZE-14)

Everybody, the best professors from MIT and London, all go to Beijing and Shanghai. They become very, very selective now. The platform is very high now, so obvious and so quick. It may be better for my career to go back to China, to work there for a few years. (Interview-AZE-14)

The way research is conducted is also changing dramatically in China, at least in most 'hard' sciences, and in some social sciences such as economics. Interview-CAE-1, who studied at Tsinghua, worked there after obtaining his PhD from the USA and only recently joined Ivy, noticed this and said:

In terms of academic culture and style, there is increasing similarity between China and Australia in many disciplines. When I was there, I was with a new department. The academic environment was pretty much like here. The way they do research was not that different from overseas now, (which is) quite different from when I was a student there. When I was there, I took part in reviewing some major grant proposals. I felt 'Wow, amazing, some of them are really good'. The research was done in exactly the same way as those in the western world. (Interview-CAE-1)

This was confirmed by the observation by another participant:

When I was at Fudan, I found out that the research there was quite good, much at the international level. I have seen this trend during recent years when I am invited to review manuscripts submitted to academic journals. Many authors are from mainland China. There has been a great improvement in the quality of their work. Ten years ago, the quality was problematic with poor English. Now, it is quite different.

(Interview-CQE-4)

\section{Concluding observations}

The global circulation of epistemic currents, including those among diasporic communities, challenges our longstanding notion of space and place (Tsolidis, 2001). Diasporic intellectuals and the transnational networks they establish, as part of the wider phenomenon of increased global mobility undergirded by greater density and diffusion of information technology, could tilt the balance towards countries such as China and create far more complex and decentralised, twoway knowledge flows. Once seen as a permanent loss, the exodus of the highly skilled is now more often seen as both a loss and a potential gain for the country of origin (Lowell \& Gerova, 2006; Wickramasekara, 2002).

Our Ivy study shows that the diaspora group can, under the right circumstances, contribute much to both China and Australia, and are keen to do so. Undergirded by their education and experience from China, post-graduate degrees from Australia, and posts in a system that is better positioned in the global network (Altbach, 1998), they can not only help mainland scholars enter the international knowledge system, but also maintain broad contacts with other scholars in the world and conduct various international research collaborations. As potential knowledge-bridges, they can play a unique role in integrating China more closely with the international scholarly community.

Despite the fact that, in practice, several factors restricted successful research 
collaboration, they have maintained a strong passion for China. At the same time, as China emerges as a global power, this group could contribute strategically to Australia's global positioning as well. As Interview-CAE-1 pointed out,

There are contributions these Chinese scholars could make for this country and for China as well. Australia is a very special western country. It is in Asia and the linkages in the future will become stronger and stronger. For example, in my field, colleagues from both China and Australia complement each other and can work together well.

With rich experiences in different cultures and intellectual traditions, such individuals are a particularly important asset in an era of intensified globalisation, and thus deserve special consideration at both institutional and national level.

Sadly, however, relative to some other Australian universities, several interviewees at Ivy indicated they felt these qualities were under-valued:

My faculty just wants us to be academics. If there is anything between China and Australia, they would want us to do it. But I do not feel obviously encouraged to build bridges to China. (Interview-CAE-1)

Compared with other Australian universities, Ivy has paid less attention to collaborations with Chinese universities, at least in my field. (Interview-ASS-11)

I really want to set up collaboration with mainland scholars, especially when China develops so fast. But it is somewhat ironic that there is little collaboration in engineering with mainland universities. We even have few doctoral students from China. (Interview-CQE-4)

This is a particularly regrettable finding, which underlines the importance of effective support and leadership among institutions and governments on both sides. The Chinese knowledge diaspora, on this account, is keen to forge such links and can contribute significantly to both scientific collaboration and strengthened cultural ties; but without basic support from both sides, such intentions may well remain unfulfilled.

\section{References}

Altbach, P.G. (1998). Comparative Higher Education: Knowledge, the university and development. London: Ablex Publishing Corporation.

Appadurai, A. (2001). Grassroots globalisation and the research imagination. In A. Appadurai (Ed.), Globalisation (pp. 1-21). Durham: Duke University Press.

Auriol, L. \& Sexton, J. (2002). Human resources in science and technology: Measurement issues and international mobility. In OECD (Ed.) International mobility of the highly skilled (pp. 13-38). Paris: OECD.

Bhagwati, J.H. \& Rodriguez, C. (1975). Welfare-theoretical analyses of the brain drain. Journal of Development Economics, 2, 195-221.

Cao, C. (2004). Chinese science and the 'Nobel Prize’ complex. Minerva, 42(2), 151-172.

Cartier, C. (2003). Regions of diaspora. In J.C.L. Ma \& C. Cartier (Eds.) The Chinese diaspora: Space, place, mobility, and identity (pp. 379-390). Lanham, MD: Rowman \& Littlefield.

Cervantes, M. \& Guellec, D. (2002). The brain drain: Old myths new realities. Observer May 07. Retrieved 19 October 2004 from http://www.oecdobsever.org 
Choi, H. (1995). An international scientific community: Asian scholars in the United States. New York: Praeger.

Dzvimbo, P. (2003). The international migration of skilled human capital from developing countries. Retrieved 5 May 2004 from http://www.worldbank.org/afr/teia/conf_0903/peter_dzvimbo.pdf

Gaillard, J. \& Gaillard, A.M. (1998). The international circulation of scientists and technologists: A win-lose or winwin situation. Science Communication, 20(1), 106-115.

Gilbert, H., Khoo, T., \& Lo, J. (Eds.) (2000). Diaspora: Negotiating Asian-Australia. St. Lucia, Queensland: University of Queensland Press.

Graduate School of Education, Shanghai Jiaotong University (2007). Academic ranking of world universities. Retrieved 28 July 2008 from http://www.arwu.org/rank/2007/ARWU2007TOP500list.htm

Grubel, H. (1987). The economics of the brain drain. In G. Psacharopoulos (Ed.), Economics of education research and studies (pp. 201-206). Oxford: Pergamon Press.

Hugo, G. (2002). Migration policies designed to facilitate the recruitment of skilled workers in Australia. In OECD (Ed.), International mobility of the highly skilled (pp. 291-320). Paris: OECD.

Hugo, G. (2006). Australian experience in skilled migration. In C. Kuptsch \& E.F. Pang (Eds.), Competing for global talent (pp. 143-145). Geneva: International Institute for Labour Studies.

Hugo, G. \& Dasvarma, G. (2008). The migration of Indian academics to Australia. Culture and identity: Re-imaging Australia and India, governance and policy India-Australia, Indian Association for the Study of Australia, Australia-India Council (AIC) and Burdwan University, St. John’s Diocesan School, Kolkata, India, (January)

Johnson, H. (1968). ‘Internationalist’ model. In W. Adams (Ed.), The brain drain (pp. 69-91). New York: The Macmillan Company.

Kapur, D. (2001). Diasporas and technology transfer. Journal of Human Development, 2(2), 265-286.

Kapur, D. \& McHale, J. (2005). Give us your best and brightest: The global hunt for talent and its impact on the developing world. Washington, D.C.: Center for Global Development.

Kuptsch, C. \& Pang, E.F. (Eds.) (2006). Competing for Global Talent (87-106). Geneva: International Institute for Labour Studies.

Kuznetsov, Y. (Ed.) (2006). Diaspora networks and the international migration of skills: How countries can draw on their talent abroad. Washington: World Bank (Institute for Development Studies).

$\mathrm{Li}$, P. (2005, October). Immigration from China to Canada in the age of globalization: Issues of brain drain and brain loss. Paper presented at the conference, “'People on the Move’: The Transnational Flow of Chinese Human Capital”, $20^{\text {th }}-21^{\text {st }}$, The Hong Kong University of Science and Technology.

Lowell, L. \& Gerova, S. (2006). Diasporas and economic development: State of knowledge. Washington D.C.: Institute for the Study of International Migration, Georgetown University.

Lucas, R. (2001). Diaspora and development: Highly skilled migrants from East Asia. Retrieved 12 August 2004 from http://www.bu.edu/econ/ied/dp/papers/dp120.pdf

Ma, L.J.C. \& Cartier, C. (Eds.) (2003). The Chinese diaspora: Space, place, mobility, and identity. Lanham, MD: Rowman \& Littlefield.

Mahroum, S. (1999). Highly skilled globetrotters. In OECD (Ed.), Mobilising human resources for innovation: Proceedings of the OECD workshop on science and technology labour markets. Paris: OECD. Retrieved 10 January 2006 from http://www.oecd.org/disti/sti/s_t/inte/prod/human_resources.htm.

Meyer, J-B. \& Brown, M. (1999, June) Scientific diasporas: a new approach to the brain drain. Paper presented at the world conference on science, Budapest.

Meyer, J-B., Kaplan, D., \& Caran, J. (2001). Scientific nomadism and the new geopolitics of knowledge. Oxford: 


\section{UNESCO.}

Mullan, F., Politzer, R.M., \& Howard, C.D. (1995). Medical migration and the physician workforce: International medical graduates and American medicine. The Journal of American Medical Association, 273(19), 15211527.

Namgung, S.U. (2009). Returning scholars in Korean higher education: A case study of internationalisation of higher education. Unpublished doctoral thesis, University of Sydney.

National Science Foundation (NSF) (2010). Science and Engineering Indicators 2008, National Science Foundation (Table 5-22: S\&E articles, citations, and international citations, by selected region/country: 1998 and 2008). Retrieved 30 November 2009 from http://www.nsf.gov/statistics/seind10/tables.htm\#c5.

Olesen, H. (2002). Migration, return and development: An institutional perspective. Expert working paper prepared for the Centre for Development Research Project, Migration-Development Links: Evidence and Policy Options. Copenhagen, Centre for Development Research.

Organisation for Economic Cooperation and Development (OECD) (2008). OECD Reviews of Innovation Policy: China. Paris: OECD.

Partinkin, D. (1968). 'Nationalist’ model. In W. Adams (Ed.), The brain drain (pp. 92-108). New York: The Macmillan Company.

Reis, M. (2004). Theorising diaspora: Perspectives on ‘classical' and ‘contemporary’ diaspora. International Migration, 42(2), 41-60.

Rizvi, F. (2000). International education and the production of global imagination. In N. Burbules \& C. Torres (Eds.), Globalisation and dducation: Critical perspectives (pp. 205-226). London: Routledge.

Salt, J. (1997). International movements of the highly skilled. OECD occasional paper No. 3. Paris: OECD.

Saxenian, A. (2006). The new Argonauts. Regional case study methods: Integrating quantitative and qualitative knowledge. California: Thousand Oaks.

Shuval, J. (2000). Diaspora migration: Definitional ambiguities and a theoretical paradigm. International Migration, 38(5), 41-57.

Solimano, A. (2002). Globalising talent and human capital: Implications for developing countries. Santiago: UN.

Solimano, A. \& Pollack, M. (2004). International mobility of the highly skilled: The case between Europe and Latin America. Santiago: ECLAC.

Tsolidis, G. (2001). Schooling, diaspora and gender. Buckingham: Open University Press.

Wang, G. (2001). Don't leave home: Migration and the Chinese. Singapore: Times Academic Press.

Welch, A. \& Cai, H-X. (2010). Internationalisation of Chinese universities. Retrospect and prospect. In J. Ryan (Ed.), Understanding China's education reform: Creating cross cultural knowledge, pedagogies and dialogue. London: Routledge (In Press).

Welch, A.R. \& Zhang, Z. (2007, November). The rise of the Chinese knowledge diaspora: Possibilities, problems and prospects for South and North. Paper presented at the World University Network Forum Realising the Global University, London.

Wickramasekara, P. (2002). Policy response to skilled migration: Retention, return and circulation. Geneva: International labour Organisation.

Wong, B. P. (2006). The Chinese in Silicon Valley. Lanham, MD: Rowman \& Littlefield.

World Bank (2000). Higher education in developing countries: Peril and promise. Washington D.C.: World Bank.

Zweig, D. (2006). Learning to compete: China's efforts to encourage a 'reverse brain drain'. In C. Kuptsch \& E.F. Pang (Eds.), Competing for global talent (pp. 187-213). Geneva: International Institute for Labour Studies.

Zweig, D., Chen, C., \& Rosen, S. (2004). Globalisation and transnational human capital: Overseas and returnee 
scholars to China. The China Quarterly, 179, 735-757. 